\title{
Detection of an increased incidence of early gastric cancer in patients with intestinal metaplasia type III who are closely followed up
}

\author{
T Rokkas, M I Filipe, G E Sladen
}

\begin{abstract}
Because early gastric cancer is associated with a much better prognosis than advanced disease, its diagnosis is important. Over a 12 year period (1976-87), a progressive increase in the incidence of early gastric cancer was observed. Twenty four of the $718(3.3 \%)$ consecutive gastric resections for gastric cancer in this period were in patients with early gastric cancer. Six of the 24 were diagnosed in the first six year period (1976-81) and 18 in the second six year period $(1982-87)(p<0.01)$. This increase was observed during the prospective phase of the study, when all patients diagnosed on initial biopsy specimen as showing type III intestinal metaplasia underwent follow up endoscopy and biopsy at six to 12 month intervals. Eleven of the 18 with early gastric cancer detected in this period were diagnosed as a direct result of this follow up. We conclude that early gastric cancer can be diagnosed with increasing frequency if patients with type III intestinal metaplasia are closely followed endoscopically.
\end{abstract}

Gastric cancer is a lethal disease if diagnosed late. In most published reports the prognosis has been exceedingly poor, with five year survival rates approaching 10-15\%. ${ }^{12}$ Studies from Japan have shown encouraging results when gastric cancer is diagnosed early and confined to the mucosa and submucosa, with five year survival rates exceeding $90 \%$ at this stage of the disease. ${ }^{3}$ Intestinal metaplasia is generally considered a precursor of gastric cancer ${ }^{45}$ but its common occurrence and presence in both benign and malignant conditions limits its value as an indicator of risk. Recent studies, however, have identified types of intestinal metaplasia that may have different malignant potentials. Thus, an association between a variant of intestinal metaplasia, with incomplete cell differentiation and sulphomucin secretion (type III), and the intestinal type of gastric cancer has been suggested..$^{6-11}$ Because of this, detection of type III intestinal metaplasia may be of value in the early diagnosis of gastric cancer. ${ }^{49}$ The present study was designed to examine the usefulness of identifying type III intestinal metaplasia as a marker of increased cancer risk and the pattern of incidence of early gastric cancer at Guy's Hospital over a 12 year period.

Study design and methods

All sections of preoperative endoscopic gastric biopsy specimens and gastrectomy specimens for the 12 year period studied were examined by the same histopathologist (MIF). For the first six years (1976-81) the study was retrospective, but for the next six year period $(1982-87)$ it was prospective. In the second half of the study patients diagnosed on initial biopsy specimen as having type III intestinal metaplasia were followed with endoscopy and biopsy at six to 12 month intervals.

A total of 718 gastrectomies for gastric cancer were performed at Guy's Hospital between 1976 and 1987. The clinical notes and histology reports were reviewed in all cases. From this group two subgroups of patients were identified - one $(n=24)$ with early gastric cancer and the other $(n=694)$ with advanced disease. Early gastric cancer was defined as malignancy confined to mucosa or submucosa, with or without regional lymph node involvement. ${ }^{12}$ The histology of patients with early gastric cancer was reexamined and survival data were obtained and analysed.

All material was fixed in $10 \%$ formol saline and routinely embedded in paraffin wax. Serial

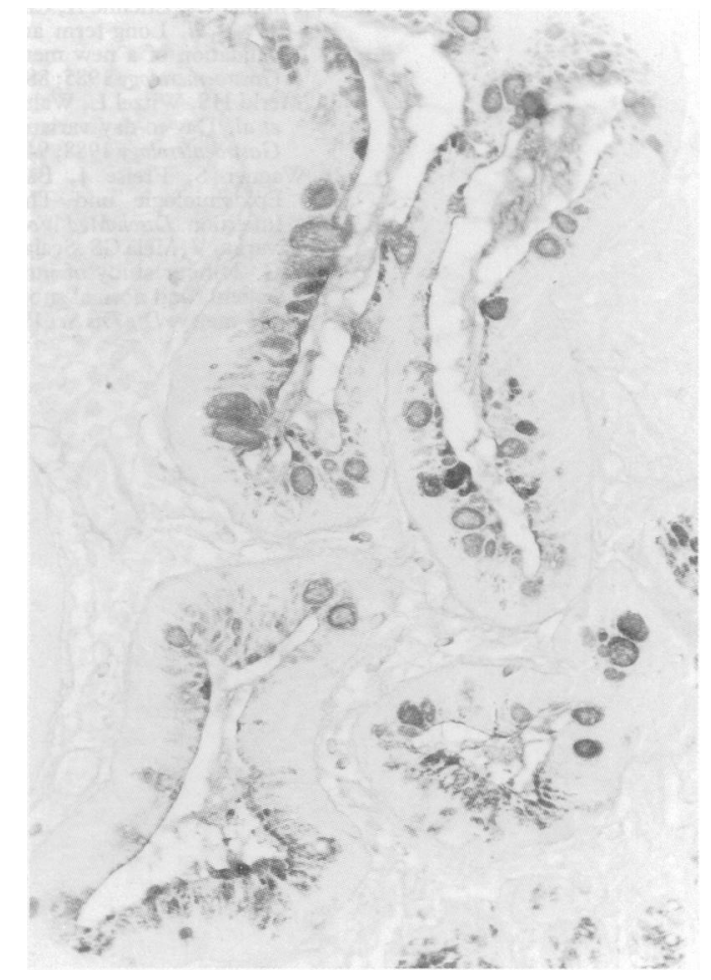

Figure 1: Intestinal metaplasia type III: The crypts are tortuous and lined by columnar mucous cells secreting predominantly suphomucins (black) and interspersed goblet cells containing a mixture of sialo- or sulphomucins goblet cells containing a mixture of sialo- or sulphomucins
(dark grey/black), or both. (High iron-diamine/alcian blue original magnification $\times 440$. 


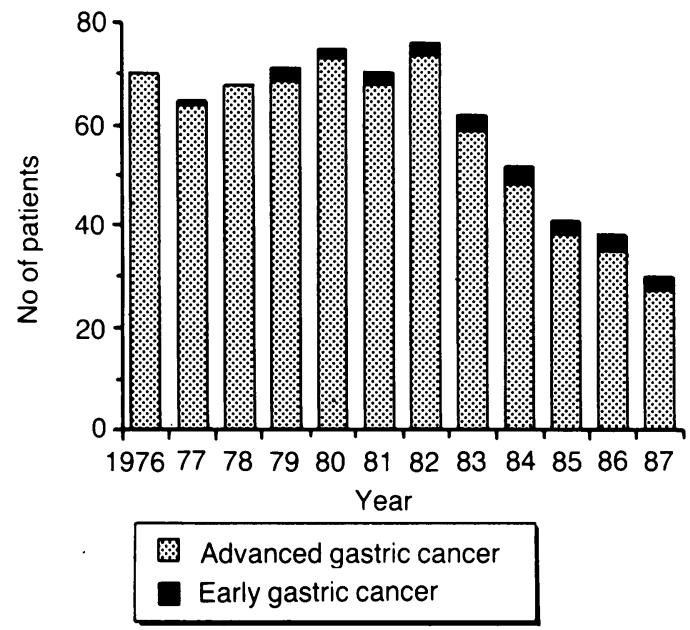

Figure 2: Yearly pattern of gastric cancer over the period 1976-87.

sections were cut, stained with haematoxylin and eosin and the following techniques for mucins: alcian blue ( $\mathrm{pH} 2 \cdot 5$ )/periodic acid Schiff (AB-PAS) and high iron-diamine/alcian blue $\mathrm{pH}$ $2 \cdot 5$ (-HID/AB) to identify neutral, sialo- and sulphomucins. ${ }^{13}$ Intestinal metaplasia was classified according to Filipe and Jass, 9 as follows:

Type I: mature absortive and goblet cells, the latter secreting sialomucins;

Type II: few or absent absortive cells, presence of columnar 'intermediate' cells in various stages of differentiation secreting neutral and acid sialomucins and goblet cells secreting sialomucins or occasionally sulphomucins, or both;

Type III: cell differentiation more noticeable than in type II, 'intermediate' cells secreting predominantly sulphomucins and goblet cells secreting sialo- or sulphomucins, or both (Fig 1).

\section{STATISTICAL ANALYSIS}

Results are expressed as mean (SEM). The $\chi^{2}$ test with Yates's correction, the Fisher's exact test, and the Mann-Whitney $U$ test were used for statistical analysis as appropriate. A p value less than 0.05 was considered to be significant.

\section{Results}

Over a 12 year period (1976-87), 718 gastrec-

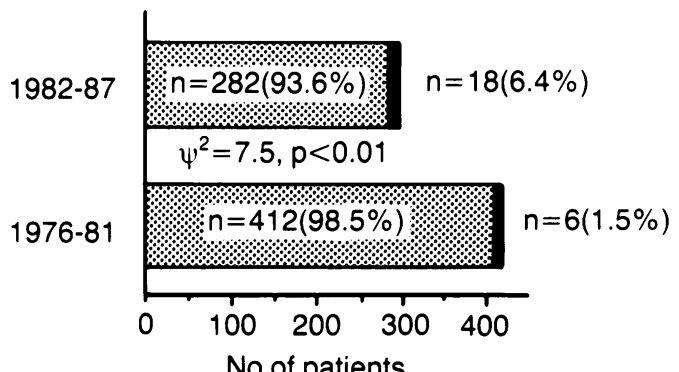

Advanced gastric cancer
Early gastric cancer

Figure 3: Comparison of early gastric cancer percentages between the periods 1976-82 and 1982-87. tomies were performed and there was a progressive decline in the number of gastric resections for gastric cancer performed per year (Fig 2). Over the whole study period, 24 cases of early gastric cancer were diagnosed $(17 \mathrm{men} / \mathrm{seven}$ women, mean age $68.4(2.4)$ years). All early gastric cancers were ulcerated lesions initially, some of which healed with medical treatment. The percentage of early disease increased from $1.5 \%$ (six cases) for the period $1976-81$ to $6.4 \%$ (18 cases) for the period 1982-87 ( $\mathrm{p}<0.01)$ (Fig $3)$.

During the period 1982-87, a total of 2286 biopsy specimens were examined, of which $4 \%$ were classified as type III intestinal metaplasia (range per year $1 \cdot 7 \%-6 \cdot 8 \%$ ) (Fig 4). Eighty patients presented at some stage with type III intestinal metaplasia. In 22 this lesion coexisted with carcinomas five of which were early gastric cancers. Follow up was carried out in 26 patients, of whom 11 developed early gastric cancer, four had associated gastric ulcer, and 11 are under surveillance. The remaining patients were either lost to follow up or had not been recalled at the end of 1988. In two patients early gastric cancer was not associated with type III intestinal metaplasia (Fig 4).

Intestinal metaplasia type III was present in 22 of $24(91.6 \%)$ of the cases - that is, in all six cases diagnosed during the first period and in 16 of 18 during the second period. In all six cases $(100 \%)$ from the first period and in seven of 18 (39\%) from the second, the diagnosis of early gastric cancer arose from the initial gastroscopy. In the remaining 11 of $18(61 \%)$ cases detected during the second period, the diagnosis was made during the course of regular endoscopic surveillance (at six month to one year intervals) of patients identified as having type III intestinal metaplasia. This difference was statistically significant $(p<0 \cdot 01)$. In the 11 patients undergoing surveillance, the median time interval between the initial endoscopy and the diagnosis of early gastric cancer was 25 months (range 1230 months).

Most (17) of the early gastric cancers were the intestinal type and well/moderately differentiated (13) - with the remainder either poorly differentiated (5) or signet ring type (6). There was submucosal infiltration in five cases $(20.8 \%)$, and in another five there was involvement of the regional lymph nodes. Survival data after surgery were available in all 24 patients with early gastric cancer. Twenty one $(81 \%)$ patients were alive, followed up for a mean (SEM) period of $5(0.54)$ years (range 1-9) after surgery. Of the three deaths, two were cancer related (two and three years after surgery) and one was not cancer related. Neither the presence of submucosal infiltration nor positive nodes significantly reduced survival.

\section{Discussion}

In this study there was a progressive decline in the number of gastric resections performed yearly for gastric carcinoma. Although this could be attributed to improved preoperative exclusion of patients with widespread disease, it may also reflect a real decline in the incidence of gastric 


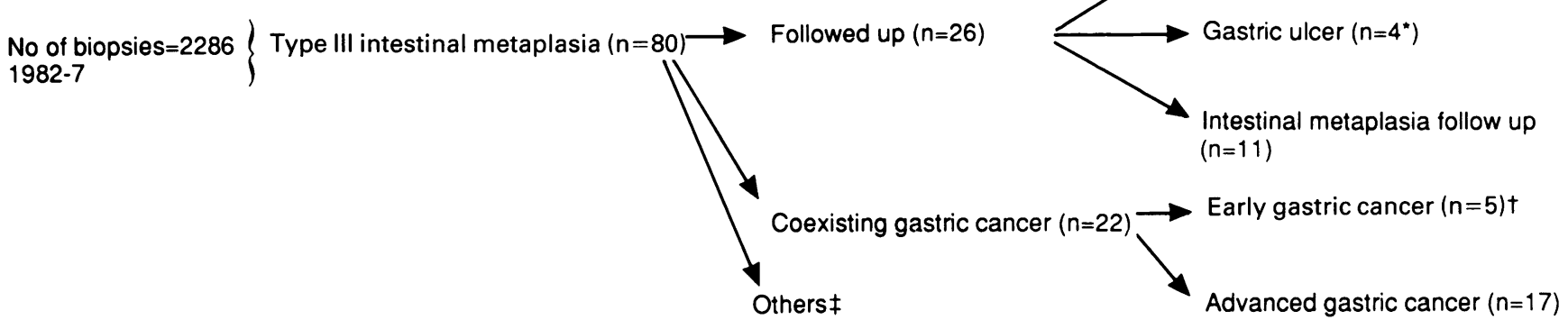

Figure 4: Intestinal metaplasia type 3 and early gastric cancer. ${ }^{\star}$ Operated on or returned to normal. $\dagger$ Two others were not associated with type III intestinal metaplasia. $\ddagger$ Lost to follow up or not yet recalled.

cancer. $^{14}$ is Despite this decline, there was a progressive increase in the percentage of patients who underwent resection at an early stage, and these patients survived much longer than those with advanced gastric cancer. ${ }^{15}$ All early gastric cancers were ulcerated lesions (type III early gastric cancer according to the Japanese Endoscopic Society classification), ${ }^{16}$ and it seems that this type of cancer is associated with better survival than type I (polypoid) or type II (flat, minimally raised or minimally depressed). ${ }^{15}$ Our observation that neither submucosal invasion nor lymph node involvement changed survival in patients with early gastric cancer is similar to the Japanese $^{17} 18$ and American ${ }^{15}$ experience.

The increased detection of early gastric cancer between 1982 and 1987 seems to be associated with the follow up of patients with type III intestinal metaplasia started in 1982.

The incidence of variants of intestinal metaplasia in gastric disease has been investigated in various centres..$^{6-8101119}$ There is general agreement that types I and II intestinal metaplasia are common and prevalent in both benign and malignant conditions, while the incidence of type III intestinal metaplasia in gastric carcinoma is significantly higher compared with its presence in chronic gastritis or gastric ulcer. ${ }^{7811}$

Available data on the malignant potential of these variants of intestinal metaplasia, their natural history, and their value in surveillance for gastric cancer is scanty. Two recently published retrospective studies failed to show increased cancer risk in patients with type III intestinal metaplasia. ${ }^{2021}$ However, no firm conclusions can be drawn from these analyses as they were based on a small number of patients and a short period (eight to 10 years) of disease evolution. A large retrospective cohort study was initiated in Slovenia (a high risk cancer area) involving approximately 10000 gastric biopsy specimens taken from 2000 patients between 1967 and 1976 (unpublished data). Preliminary findings suggest a greater cancer risk associated with the presence of sulphomucin secreting intestinal metaplasia than with type I intestinal metaplasia.

Data from another prospective study, begun in 1982 to assess the pattern of intestinal metaplasia variants in the evolution of chronic atrophic gastritis and gastric ulcer, ${ }^{22}$ showed that type III intestinal metaplasia is often related to chronicity of disease, can evolve to dysplasia and, in gastric ulcer patients, is often associated with delayed healing or recurrence. These observations suggest that type III intestinal metaplasia may be useful in screening these patients for early detection of cancer, particularly as it has been shown that a number of early gastric cancers present clinically, radiologically, and endoscopically as benign gastric ulcers. ${ }^{23}$

This study supports this notion in that in 59\% of patients with early gastric cancer diagnosed between 1982 and 1987, the diagnosis was made during endoscopic surveillance of patients with gastric ulcers associated with type III intestinal metaplasia. This is particularly important for ulcerated early gastric cancers, which frequently go through a healing phase ${ }^{24}$ or even heal completely giving the impression that the lesion is benign. ${ }^{23} 25-27$

In conclusion, we have shown that at our Institution early gastric cancer is being diagnosed with increasing frequency and this seems to be related to close endoscopic surveillance of patients with type III intestinal metaplasia. We believe that type III changes are precursor lesions of early gastric cancer and their presence should lead to prolonged endoscopic surveillance. If the validity of this study is confirmed by others, the cost implications will have to be considered.

We thank Professor D A Levison for the constructive criticism of the text and Mrs Angela Sandey for her excellent technical assistance.

1 Fielding JWL, Roginski C, Ellis DJ, et al. Clinicopathological staging of gastric cancer. Br F Surg 1974; 71: 677-80

2 Cancer Research Campaign (Fact sheets 8,9, and 10). London 1988.

3 Kitaoka H, Yoshikawa K, Hirota T, Itabashi M. Surgical treatment of early gastric cancer. Fapanese $\mathcal{F}$ Clinical Oncology 1984; 14: 283-93.

4 Correa P. A human model of gastric carcinogenesis. Cancer Research 1988; 48: 3554-60.

5 Morson BC, Jass JR, Sobin LH. Precancerous lesions of the gastrointestinal tract. London: Baillière Tindall, 1985.

6 Sipponen P, Seppala K, Varis K. et al. Intestinal metaplasia with colonic-type sulphomucins in the gastric mucosa; its with colonic-type sulphomucins in the gastric mucosa; its
association with gastric carcinoma. Acta Pathol Microbiol Scand 1980; 88: 217-24.

7 Rothery GA, Day DW. Intestinal metaplasia in endoscopic biopsy specimens of gastric mucosa. $\mathcal{J}$ Clin Pathol 1985; 38: 613-21.

8 Filipe MI, Potet F, Bogomoletz WV, et al. Incomplete sulphomucin-secreting intestinal metaplasia for gastric cancer. Preliminary data from a prospective study from three centres. Gut 1985; 26: 1319-26.

9 Filipe MI, Jass JR. Intestinal metaplasia subtypes and cance risk. In: Filipe MI, Jass JR, eds. Gastric carcinoma. Edinburgh: Churchill Livingstone, 1986: 87-115.

10 Huang C, Xu J, Huang J, Mung X. Sulphomucin colonic Type intestinal metaplasia and carcinoma of the stomach. Cancer 1986; 57: 1370-5.

11 Silva S, Filipe MI. Intestinal metaplasia and its variants in the gastric mucosa of Portuguese subjects: a comparative analy17: $988-95$.

12 Murakami T. Pathomorphological diagnosis. Definition and 
gross classification of early gastric cancer. In: Murakami T, ed. Early gastric cancer. Gann Monogr Cancer Res 11 . Baltimore: University Park Press, 1972: 53-5.

13 Filipe MI, Lake BD. Histochemistry in pathology. Edinburgh: Churchill Livingstone, 1983.

14 Devesa SS, Silverman DT. Cancer incidence and mortality trends in the United States. 1935-1974. F Natl Cancer Inst 1978; 60: 545-71.

15 Green PHR, O'Toole KM, Slonim D, Want T, Weg A Increasing incidence and excellent survival of patients with early gastric cancer. Experience in a United States medical center. $A m$ F Med 1988; 85: 658-61.

16 Kawai K. Diagnosis of early gastric cancer. Endoscopy 1971; 1 : 23-8.

17 Hayashida T. End results of early cancer collected from 22 institutions. Stomach and intestine 1969; 4: 1077-85.

18 Kidokoro T. Frequency of resection, metastasis and five year survival rate of early gastric carcinoma in a surgical clinic. In: Murakami T, ed. Early gastric cancer. Gann Monogr In: Murakami T, ed. Early gastric cancer. Gann Monogr
Cancer Res 11. Baltimore: University Park Press, 1972:

1.9 Murray LA, Williams GT. Sulphomucin - containing intestinal metaplasia in gastric biopsies - one year's experience. $f$ Pathol 1984; 142: A24.
20 Ectors N, Dixon MF. The prognostic value of sulphomucin positive intestinal metaplasia in the development of gastric positive intestinal metaplasia in the dev.

21 Ramesar KCRB, Sanders DSA, Hopwood D. Limited value of type III intestinal metaplasia in predicting risk of gastric carcinoma. F Clin Pathol 1987; 40: 1287-90.

22 Silva S, Filipe MI, Pinho A. Variants of intestinal metaplasia in the evolution of chronic atrophic gastritis and gastric ulcer. A follow up study. Gut 1990; 31: 1097-104.

23 Dombal de FT, Price AB, Thompson $\mathrm{H}$, et al. The British Society of Gastroenterology early gastric cancer/dysplasia survey: an interim report. Gut 1990; 31: 115-20.

24 Sakita T, Oguro Y, Takasu S, Fukutomi H, Miwa T, Yoshimori $\mathrm{Y}$. Observation of the healing of ulcerations in early gastric cancer. The life cycle of the malignant ulcer. Gastroenterology 1971; 60: 835-44.

25 Green PHR, O'Toole KM, Weinberg LM, Goldfarb JP. Early gastric cancer. Gastroenterology 1981; 81: 247-56.

26 Ito Y, Blackstone MD, Riddel RH, Kirsner JB. The endoscopic diagnosis of gastric cancer. Gastrointest Endosc 1979; 25:96-101.

27 Farini R, Farinati F, Leandro G, Mario Di F, Cecchetto A, Naccarato R. Gastric epithelial dysplasia in relapsing and non-relapsing gastric ulcer. $A m \mathcal{F}$ Gastroenterol 1982; 77: 844-53. 